\title{
Psychological Essentialism and Cultural Variation: Children's Beliefs about Aggression in the United States and South Africa
}

\author{
Jessica W. Giles ${ }^{a, *}$, Cristine Legare ${ }^{\mathrm{b}}$ and Jennifer E. \\ Samson $^{\mathbf{a}}$ \\ ${ }^{a}$ Department of Psychology and Human Development, Vanderbilt University, \\ Nashville, TN, USA \\ ${ }^{\mathrm{b}}$ University of Michigan, Ann Arbor, MI, USA
}

\begin{abstract}
The present study compared indigenous South African versus African-American schoolchildren's beliefs about aggression. Eighty 7-9 year olds (40 from each country) participated in interviews in which they were asked to make inferences about the stability, malleability, and causal origins of aggressive behaviour. Although a minority of participants from both countries endorsed essentialist beliefs about aggression, South African children were more likely than American children to do so. Results also revealed some degree of coherence in children's patterns of beliefs about aggression, such that children responded across superficially different measures in ways that appear theoretically consistent. The authors consider these findings in light of debates concerning the role of cultural forces in shaping person perception. Copyright (C) 2007 John Wiley \& Sons, Ltd.
\end{abstract}

Key words: attribution; aggression; culture

\section{INTRODUCTION}

Children's reasoning about the behaviour and mental life of other people has important implications for the ways in which they navigate the social world. Indeed, there is increasing evidence that it is important to understand children's implicit conceptions of psychology in order to gain a more complete picture of the development of a wide variety of sociocognitive attainments, such as theory of mind, achievement motivation, and social competence (Dweck, 1999; Gelman, 2003;

\footnotetext{
*Correspondence to: Jessica W. Giles, Department of Psychology and Human Development, Vanderbilt University, 230 Appleton Pl. Box 512, Nashville, TN 37203, USA.

E-mail: jessica.w.giles@vanderbilt.edu
} 
Giles, 2003). It has been argued that although the development of these 'naïve theories' of psychology may be assisted by foundational perceptual and conceptual capacities (Baron-Cohen, 1995; Bruner, 1990; Leslie, 1995), these initial capacities serve as bootstrapping mechanisms that provide the structure upon which children construct cultural knowledge about what people are generally like (Bartsch \& Wellman, 1995; Gopnik \& Wellman, 1994; see Wellman \& Gelman, 1998). According to this position, it is likely that children from different cultures will develop disparate ways of explaining human behaviour (Lillard, 1998; see Weiner, 1974).

This possibility is supported by much work in developmental and crosscultural psychology, as well as by anthropological evidence. For example, Lillard's (1998) review of cultural variations in theory of mind suggests that cultures vary widely in the extent to which their participants endorse internal or nativist explanations for behaviour (see also Choi, Nisbett, \& Norenzayan, 1999; Hofstede, 1980; Miller, 1984). Indeed, the circumstances under which people engage in such psychological essentialism have been a major focus of several converging research traditions, including those investigating the development of biological understanding, achievement motivation, and person perception (see Gelman, 2003). Psychological essentialism is the tendency to conceive of entities as having deep underlying natures that make them what they are, and that constrain potentially observable properties and behaviours (Medin, 1989; Medin \& Heit, 1999; see also Gelman, Coley, \& Gottfried, 1994, concerning essentialist reasoning in young children). When a characteristic is viewed in an essentialist way, it is thought to be a fundamental aspect of the entity that possesses it, and highly resistant to change (see Martin \& Parker, 1995).

Recent research has examined people's essentialist beliefs about a wide variety of constructs, including social categories (Giles \& Heyman, 2005; Haslam \& Levy, 2006; Hirschfeld, 1996; Rothbart \& Taylor, 1992), traits (Gelman, Heyman, \& Legare, 2005), intelligence (Dweck, 1999), and sociomoral behaviour (Giles, 2005; Giles \& Heyman, 2003; Maas, Marecek, \& Travers, 1978). An important conclusion to emerge from this research is that essentialist beliefs are more than a mere set of ontological abstractions (Haslam \& Levy, 2006); on the contrary, they have important real-world implications, notably for social decision-making. For example, essentialist beliefs about aggression have been receiving increasing attention because they are associated with a tendency to exhibit motivational helplessness in the face of social challenge (Giles \& Heyman, 2003; see also Dweck, 1999) and a tendency to make punitive judgments across a range of domains, including judgments of other people's guilt or innocence (Gervey, Chiu, Hong, \& Dweck, 1999; Giles, 2005; see Giles, 2003).

Such social ramifications underscore the importance of gaining a greater understanding of the social forces that might influence the development of essentialist beliefs about aggression. The possibility that cultural context might causally influence essentialist tendencies is reasonable in light of evidence that cultures do vary substantially in the extent to which members report essentialist beliefs (see Lillard, 1998). Many cultural processes have been posited to account for this cultural variation; one predominant trend has been to examine variations in folk psychology as a function of where cultures fall on the individualistcollectivist dimension (see Hofstede, 1980). For example, Pfeffer, Cole, and Dada (1998) found that, compared to Nigerian school children, British schoolchildren are more likely to view adolescent criminal behaviour as stable over time and internally mediated. The authors argue that the British children's greater tendency to make attributions to internal causes might be accounted for by the tendency for Western societies to emphasize individual responsibility and for 
non-Western societies to emphasize collective responsibility (see Hofstede, 1980). In recent years, however, scholars have criticized this sort of dichotomization on the grounds that it is reductionistic and fails to account for the complex interrelationships between cognition, culture, historical context, and political climate (see Dawes, 1994).

For example, a dichotomous model along individualist-collectivist lines might posit that children from non-Western cultures (who, ostensibly, are not developing under the shadow of Western social science models of causation but instead under a zeitgeist of communalism and interdependence; see Lillard, 1998) would endorse situationist and not essentialist views of sociomoral behaviour. However, one could just as easily argue that many non-Western developmental contexts, collectivist or not, have features that would seem to promote essentialist reasoning (Lutz, 1985; Shweder \& Bourne, 1991; Whiting, 1996). For instance, there is evidence that exposure to community violence, which is arguably common in some non-Western societies, may be associated with the development of essentialist beliefs about aggression (Briere \& Elliott, 1994; Fischer \& Ayoub, 1994; see also Giles, 2003). If this is indeed the case, one might expect that children from non-Western cultures with high rates of violence might endorse essentialist beliefs.

The primary goal of the present research is to examine the possibility that early elementary school-aged children growing up in different cultural circumstances might display different patterns of beliefs about the stability, malleability, and origins of aggressive behaviour (see Heyman \& Dweck, 1998, regarding the importance of the early elementary school years in the development of person perception). Specifically, the present study compares African-American children's beliefs about aggression to those of indigenous South African agemates. Although the United States and South Africa are clearly diverse societies whose many ethnic and cultural groups undoubtedly represent a range of worldviews, in the interest of maximizing direct between-group comparisons, we have decided to restrict our sample to black children from each country. Although looking at the globe, one might grossly dichotomize American and South African societies as Western and non-Western, respectively, there is reason to be sceptical about the extent to which South Africa's geographic location is an informative indicator of its citizens' folk psychology.

Growing up in a country undergoing substantial societal change in the aftermath of apartheid, indigenous South African children develop their conceptions of the social world in a dynamic context of growing urbanization, the AIDS pandemic, poverty, racial inequality, and high levels of community violence (Barbarin \& Richter, 2001; Dawes, 1994). In light of this unique sociohistoric developmental landscape, there are several reasons why South Africa provides an interesting case study through which to examine essentialist beliefs. First, indigenous South African children construct their 'naïve theories' of psychology in the wake of apartheid, a social system that many scholars believe played a critical role in maintaining political discourses that emphasize rigid social classification (Deacon, 1991; Snyman, 2005; see Haslam, 1998; Mahalingam, 2003; Verkuyten, 2003; Yzerbyt, Rocher, \& Schadron, 1997, regarding the role of essentialist beliefs in rationalizing oppressive and hegemonic social order). That this might be important for our present discussion in the sense that the tendency to view human categories as immutable, entitative, and fundamentally exclusive is an important component of psychological essentialism (see Haslam, 1998; Haslam \& Levy, 2006). Second, South African children come of age in a society replete with high levels of community violence (Dawes, 1994), which is also 
known to predict an increased tendency to make essentialist judgments (Briere \& Elliott, 1994; see Barbarin, Richter, \& deWet, 2001, for evidence that even indirect exposure to 'ambient' community violence affects the belief systems of South African children). ${ }^{1}$ Third, in light of suggestions from the anthropological literature that some African societies can actually be characterized by lay dispositionism similar to that typically found in Western societies (La Fontaine, 1985; Shweder \& Bourne, 1991; Whiting, 1996; see Lillard, 1998, for a discussion), comparing patterns of reasoning among South African and American schoolchildren has the potential to contribute to a more nuanced understanding of the unique sociocognitive legacies that specific cultures bring to the essentialism debate, above and beyond the generalizations often made about Western versus non-Western folk psychologies.

In addition to comparing patterns of essentialist reasoning in indigenous South African and African-American schoolchildren, an additional goal of the present study was to examine the coherence of individual differences in children's beliefs about aggression. This has the potential to shed light on debates regarding the extent to which children's folk beliefs about the nature of human social behaviour are indeed theory like rather than composed of isolated and unrelated notions (see Giles \& Heyman, 2005). If children's beliefs about aggression are indeed organized and systematic, we might predict that they would make judgments along one dimension that are theoretically consistent with their judgments along another (e.g. the belief that aggression is stable might be associated with the belief that change would be difficult; see Heyman \& Giles, 2004, for related evidence).

\section{METHOD}

\section{Participants}

Participants were 80 7-9-year-old children (38 males and 42 females, $M=8$ years 2 months, range $=7$ years 0 months to 9 years 10 months). Of this sample, 40 were indigenous South African (24 males and 16 females) and 40 were AfricanAmerican (18 males and 22 females). As part of a broader effort to include diverse populations in psychological research, participants from both countries were recruited from schools serving lower income, ethnically diverse urban populations. Interviews were conducted in English.

\section{Procedure}

Children participated in a single 20-min individual interview conducted in a quiet office at their school. At the beginning of each interview, participants were told that the experimenter was 'talking to kids about what people are like' and were asked to respond to a series of questions about story characters. For questions in which the gender of story characters was specified, half of the participants were presented with scenarios involving exclusively male characters, and the other half were presented with exclusively female characters. Ethnicity of story characters was not stated.

These questions were grouped into two sections, a Sociomoral Stability section and a Beliefs about Aggression section. Although these measures tap into similar constructs, both are stand-alone measures that have been used in previous research to examine children's essentialist reasoning, although not always in conjunction with one another (Sociomoral stability: Giles \& Heyman, 2003; 
Heyman \& Dweck, 1998; Beliefs about aggression: Giles \& Heyman, 2004; Heyman \& Giles, 2004). We decided to include both of these alternate measures of essentialism because we felt that (1) both research trajectories could benefit from an examination of how results might compare cross culturally, and (2) it is important to examine how these measures map onto one another. This is akin to the practice of including two conceptually overlapping measures of authoritarianism or of aggressive behaviour in social psychology research.

\section{Sociomoral stability}

In this section of the interview, which always appeared first, children were presented with three scenarios in which a character behaves in an antisocial manner. Following each scenario, children were asked to predict whether the character would continue to behave in a similar manner well into the future. These scenarios, which were presented in random order, are described for female characters: (1) 'Imagine there is a new girl in your class. She steals people's things, calls people mean names, and trips kids at recess. Do you think this new girl will always act this way?'; (2) 'Imagine you see a girl who takes another kid's lunch, steps on the sandwich, and then spills the drink. Do you think she will stop acting this way when she gets older?'; and (3) 'Imagine a 5-year-old girl who gets into trouble a lot at school. Some people think she will keep getting into trouble even when she's 10. Do you think this is right or wrong?'

This measure was adapted from ones used in Heyman and Dweck (1998), Heyman, Dweck, and Cain (1992), but questions were simplified and shortened in Giles and Heyman (2003) for ease of comprehension. Additionally, unlike the questions asked in Heyman et al. (1992) and Heyman and Dweck (1998), in which endorsement of sociomoral stability was always indicated by a 'yes' response, questions in the present study were written such that sociomoral stability was endorsed by a 'yes' response on one item, a 'no' response on another item, and a 'right' response on a third item. Questions were asked in this way to ensure that participants were encouraged to consider each individually and not rely on providing the same responses across questions. Additionally, this allows for a determination of stability beliefs separate from a simple word response bias.

A stability-endorsing response was always given a score of 1, and a stabilityrejecting response was always given a 0 . Scores were summed across the three items to yield a measure of sociomoral stability. Kuder-Richardson-20 (KR-20) for this measure was $0.72 .^{2}$ Participants who never endorsed sociomoral stability or who endorsed it only once $(N=54)$ were classified as sociomoral stability rejecters; participants who endorsed sociomoral stability two or three times $(N=26)$ were classified as sociomoral stability endorsers (see Giles \& Heyman, 2003; Heyman \& Dweck, 1998). As in Giles and Heyman (2003), children were divided into two groups based on their responses to the sociomoral stability measure, because the underlying construct was theorized to be a dichotomous variable (see Dweck \& Leggett, 1988; Levy \& Dweck, 1999, for a discussion of the theoretical and empirical basis for this conceptualization). It should be noted that children were asked about stability rather than change, because previous research has suggested that questions about whether a character will change are almost always endorsed (see Heyman \& Dweck, 1998).

\section{Beliefs about aggression}

In this section of the interview, participants heard a brief vignette that read as follows: 'I know a girl/boy who is mean. S/ he likes to hurt other kids.' Following 
presentation of this vignette, children were given two measures. Each measure contained three questions each, presented in random order.

Essentialist beliefs: The first measure assessed essentialist beliefs about aggression; in particular, participants were asked to make inferences about stability ('Do you think this girl has always acted this way?'), origins ('Was this girl born this way, or did something happen to make her this way?'), and malleability ('Can this girl stop being this way?'). For each of these questions, responses consistent with an essentialist framework (i.e. stable, resistant to change, internally driven) were scored a 1, and responses inconsistent with such a framework were scored a 0 . When items offered two response options, these options were presented in random order across participants. Responses to these three items were looked at separately, but were also summed to create an overall Essentialist beliefs score, ranging from 0 (no essentialist judgments) to 3 (essentialist judgments on all items). KR-20 for this measure was 0.64.

Beliefs about intervention: This measure included three items assessing participants' beliefs about the potential effectiveness of different intervention strategies ('Could reminding this girl that it is wrong to be mean help her to change?,' 'Could showing this girl how to make friends help her to change?,' and 'Could telling this girl about other people's feelings help her to change?'). For each of these items, a 'Yes' response was scored a 1, and a 'No' response was scored a 0 . Responses to these three items were summed to create an overall Intervention score, ranging from a 0 (no interventions would help) to 3 (all interventions would help; KR-20 for this measure was $0.43^{3}$ ).

\section{RESULTS}

\section{Initial Analyses}

Initial stepwise regression analyses revealed no significant effect of participant age, participant gender, or character gender within either the American or the South African sample, so these variables were dropped from subsequent analyses. In addition, in the Intervention measure, there was no effect of type of intervention strategy presented.

\section{Inferences as a Function of Nationality}

\section{Sociomoral stability}

The South African children were more likely than the American children to endorse the notion of sociomoral stability, $M=1.50$ versus 0.70 out of 3 , $F(1,78)=18.35, p<0.0001$. Similarly, when treating sociomoral stability endorsement as a categorical variable, there were significantly more sociomoral stability endorsers in the South African sample than in the American sample, $48 \%$ versus $18 \%, \chi^{2}(1)=8.21, p<0.01$. Of note is that even though this difference was statistically significant, sociomoral stability endorsers represented a minority of participants in both groups, as has been the case in previous studies of this construct (Giles \& Heyman, 2003; Heyman \& Dweck, 1998); see the discussion section for an explanation of why this might be the case.

\section{Beliefs about aggression}

Compared to American children, the children in the South African sample scored significantly higher on the essentialist beliefs measure than did children in 
the American sample, $M=1.95$ (S.D. $=0.90)$ versus 0.95 (S.D. $=0.85$ ) out of 3, $F(1,78)=26.09, p<0.0001$. Considering each component of the essentialist beliefs scale separately, South African children were more likely than American children to view aggression as stable over time, $63 \%$ versus $28 \%, \chi^{2}(1)=10.12, p<0.01$; more likely to view aggression as inborn, $50 \%$ versus $20 \%, \chi^{2}(1)=8.11, p<0.01$; and more likely to view aggression as unmalleable, $73 \%$ versus $48 \%, \chi^{2} \times$ $(1)=9.54, p<0.01$. Children in the South African sample were marginally less likely to view intervention as effective, $M=1.60$ versus 1.91 out of $3, F \times$ $(1,78)=2.88, p<0.10$.

\section{Individual Differences}

In addition to these between-group findings, several patterns of individual differences emerged. These differences clustered largely around predictable patterns of reasoning among participants who endorsed sociomoral stability. For example, when taken as a continuous variable, sociomoral stability beliefs were positively correlated with essentialist beliefs, $r(78)=0.23, p<0.05$ (disattenuated correlation $=0.34)$. Consistent with previous research (e.g. Heyman \& Giles, 2004), sociomoral stability beliefs were negatively correlated with a tendency to view interventions as potentially effective, $r(78)=-0.31, p<0.05$ (disattenuated correlation $=-0.56$ ), as were essentialist beliefs, $r(78)=-0.42, p<0.01$ (disattenuated correlation $=-0.80$ ). These associations held for both samples, suggesting that despite between-group differences in essentialist tendencies, when essentialist reasoning does occur, it is similarly coherent in both groups.

\section{DISCUSSION}

The present research points to significant variability both within and across cultures in children's beliefs about the nature of aggression.

\section{Cross-cultural Findings}

First, on a variety of measures, indigenous South African 7-9-year-olds appeared more likely than American agemates to view aggression as inborn and stable over time. Such differences in person perception across nationalities highlight the importance of carefully thinking about the ways in which results of basic research in sociocognitive development might vary as a function of the particular demographics of the samples used (see Graham, 1992). This kind of demonstration of cross-national differences signals an important early step in clearly beginning to articulate the ways in which conceptions of aggression might vary as a function of cultural context. Although it is difficult to draw firm conclusions about the possibility of a causal role of culture in the development of person perception, in part because it is prohibitive to randomly assign children to grow up in different societies, the present results do argue against the notion of universality across environmental contexts in the development of implicit theories of aggression.

It is important to point out, however, that many children in both groups viewed aggression as malleable. This finding is consistent with Lockhart, Chang, and Story's (2002) notion of protective optimism. In their work, they find that a significant percentage of elementary school-aged children hold optimistic views of the capacity for people to change their traits or characteristics, even ones that 
are veridically difficult to change (e.g. height, eye colour). They explain that this optimism enables children to persist in trying to learn life skills that are extremely challenging, such as walking, reading, and writing. In the aggression domain, we might imagine that optimism is protective in the sense that it enables children to work out problems with classmates, siblings, or others who might behave aggressively towards them. In other words, we might argue that optimism in this domain enables a process of conflict resolution.

\section{On the role of culture in shaping beliefs}

If culture does play a causal role in the development of essentialist beliefs about aggression, what mechanisms might drive such an effect? One possibility is that children receive explicit cues from cultural avenues (e.g. folk history, peers, common clichés, etc.) that they then incorporate into their developing beliefs about people. Such a possibility is in line with the work of Dweck (1999), who has repeatedly shown that essentialist messages influence children's behaviour and indeed their own patterns of reasoning.

This possibility is an instance of a broader tendency for cultural worldviews to create and maintain frameworks for making sense of person information (see Hacking, 1995; Lillard, 1998). Along these lines, Deacon (1991) and Snyman (2005) have articulated the argument that the historical context of apartheid has maintained a cultural legacy of essentialism in South Africa, one that encourages the division of humans into rigid social classifications.

Another possibility is that exposure to violence may encourage the development of essentialist beliefs (see Giles, 2003). Consistent with this possibility, many South African social scientists (e.g. Dawes, 1994) have spoken of the sociocognitive risks that South African children face growing up in a society characterized by high rates of community violence (although certainly the same has oft been said of the United States, see Conoley \& Goldstein, 2004; see Endnote 1). It may be useful to explain how this possibility might be reconciled in terms of the broader social psychology literature. On first glance, covariation accounts (e.g. Kelley, 1967; Schuster, Ruble, \& Weinart, 1998) seem to suggest that high rates of violence might actually decrease person attributions and increase situational attributions. For one thing, we might be more likely to agree that this would be the case if it were true that most people in a community with high levels of violence were actually violent, because then such behaviour would be neither salient nor distinct. However, we contend that this is not the case. Although rates of violence are relatively high in South Africa, they are no means indicative of the possibility that all or even most people living in these children's community are violent. On the contrary, violent crime there is still perpetrated by the few rather than by the many.

Another reason we disagree with the possibility that high rates of violence might decrease essentialist reasoning is that across many domains of person perception, prevalence does not preclude rampant essentialist reasoning: for example, people commonly view romantic and physical attraction in essentialist ways (e.g. observe the prevalent reference in popular culture to 'chemistry'; see Haslam \& Levy, 2006, and also Heyman \& Giles, 2006).

\section{Links to reasoning about other human characteristics}

Whether indigenous South African children might also be similarly more likely to essentialize human behaviour in other domains, or whether the present effect is specific to reasoning about aggression, awaits further research. Consistent with 
this possibility, there is evidence that some cultures are more likely than others to make person-centred rather than situationist attributions across the board (see Lillard, 1998, for a review). However, by the same token, there is also evidence to suggest that the tendency to essentialize is at least to a certain extent domain specific (or rather, according to Gelman, 2003, that it is a domain-general tendency that is instantiated differentially across domains; see also Giles \& Heyman, 2004). Future work should endeavour to broaden our examination of essentialist tendencies in these cultural groups across domains, and to begin to articulate the extent to which, and the mechanism by which, cultural forces might exert a causal effect on children's developing belief systems.

\section{Individual Differences}

Despite evidence for intergroup differences in children's patterns of reasoning, it is still the case that some children in the present study were more prone than others to make essentialist inferences (because the measures used showed modest internal consistency, this is most evident when disattenuated correlations are examined). Why might this be the case? Children's particular social contexts (see Rowe \& Plomin, 1981) could help explain why individual differences might emerge in the tendency to engage in essentialist reasoning (see Weiner, 1974). For example, the patterns of evaluative feedback that children receive regarding their own behaviour appear to influence the development of essentialist beliefs (see Dweck, 1999; Dweck, Kamins, \& Mueller, 1997; Graham, 1984; Mueller \& Dweck, 1998). There is evidence that exposing children students to global evaluative judgments increases the likelihood that they will endorse global or stable views of human characteristics (see Dweck, 1999). In addition, children who have suffered from persistent exposure to violence are more likely than other children to attribute the cause of negative events to internal, global, and stable factors (Briere \& Elliott, 1994; Gold, 1986).

Another possibility is that children's conceptions of the nature of aggression are influenced by differential exposure to media discourse. Children who watch a lot of shows that emphasize the duality of good and evil (e.g. shows involving 'bad guys,' 'villains,' and 'heroes') may receive important cues regarding the entitativity of morality (see Gelman \& Heyman, 1999; Giles, 2005, regarding the tendency for noun labels to provoke essentialist judgments). Relatedly, parents' lay theories may also be influenced by media rhetoric surrounding violence; these conceptions may then trickle down to their children, even in indirect ways (see Eccles \& Jacobs, 1986, for related arguments).

Theoretically speaking, nativist inferences may be a result not only of exposure to social messages but also of children's tendency to co-opt readily available causal explanatory frameworks from the biological domain when explaining events in other domains (Carey, 1985; Inagaki \& Hatano, 1993; see Hickling \& Wellman, 2001, for related discussions). Inagaki and Hatano (1993) have argued that children make nativist inferences about the causes of social behaviour because they have a tendency to make use of their developing knowledge about biology when they are faced with psychological or behavioural puzzles (see also Heyman \& Gelman, 2000).

\section{Limitations and Future Directions}

One major limitation of the present study, in some sense a limitation of much work in cross-cultural psychology, is the fact that we are unable to infer causality 
from mere associations between cultural group and children's patterns of beliefs. Because children were not randomly assigned to grow up in different cultures and then followed forward over time, we cannot conclude that culture actually exerts a causal effect on children's tendency to view aggression in particular ways. However, despite this limitation, it is nonetheless important to conduct studies such as this one, at least in part because they force us to examine the basis for our own conceptions of sociocognitive development. For example, often when we talk about children's beliefs, we might really only talking about American children's beliefs; data such as that found in the present paper should serve as a reminder that American schoolchildren's responses do not necessarily reveal universal patterns (see Graham, 1992, for related arguments).

To address this issue, future research should focus on systematically investigating the particular cultural processes that might influence the development and maintenance of essentialist beliefs about aggression. One approach might be to longitudinally track biological siblings who have been separated at birth and raised in different cultures, in order to systematically examine the ways in which culture might actually shape conceptual development. An increased understanding of the effects of cultural context on the development of essentialist beliefs is important to discussions of conceptual models of aggression as well as to discussions of the nature of lay theories more generally (Pfeffer et al., 1998).

A second limitation of the present study is that it did not measure individual levels of exposure to family or community violence. Previous research (e.g. Briere \& Elliott, 1994) suggests that variability in levels of exposure to violence might predict essentialist tendencies; in the present study, we have spoken much about the importance of this relationship, but did not test it empirically. It is critical that future work substantiate these assumptions with systematic measurement, in part because it will help tease apart the relative contributions of exposure to violence and cultural inputs such as media, messages from family, etc.

A third limitation concerns the nature of our samples. We only included children from a small age range, and we therefore can say little about age-related patterns or change in belief systems over time. Sampling from a broader age range (e.g. one that includes children, adolescents, and adults) and following participants over time to examine conceptual change stands to substantially illuminate the nature of essentialist beliefs. In addition, in an effort to facilitate direct comparisons across countries, we have restricted our samples to Black children in both countries. It will be important for future research to paint a clearer picture of cultural mechanisms by carefully selecting participants across countries that themselves represent a range of ethnicities.

A related issue that is important to examine is how the particular experience of being Black might provide a unique context for the development of person perception. Assuredly, both samples in the present study belong to cultural and racial groups that have historically suffered grievous oppression, systematic discrimination, as well as more covert and implicit forms of prejudice. However, despite this similarity, the experience of being a Black child in the United States is not the same as the experience of being a Black child in South Africa. The specific ways in which these forces shape how Black children within cultures make attributions and, indeed, how they make sense of the very idea of a social category is important to think deeply about in future research.

Finally, another interesting path for future research would be to examine the ways in which children might use information about race or ethnicity to guide their inferences about aggression. There is emerging evidence to suggest that adults may be more likely to essentialize aggression in some ethnic groups more 
than others (Giles, Sullivan, \& Beaufort, 2007), perhaps in part because they are aware of heightened environmental risks among some populations (what Steinberg \& Scott, 2003, have referred to as criminogenic contexts). It will be important to follow this work up with research that examines age-related patterns in children's reasoning about the relationship between race and aggression. For example, are children more likely to essentialize aggression when they observe it in other ethnic groups than their own, as might be consistent with the hedonic relevance and attribution literatures (see Kelley, 1967)? Along these same lines, how might covariation information come into play? Might children be more likely to essentialize aggression in individuals whose ethnic group has low levels of violence, because it is then especially distinctive (see Schuster et al., 1998)? This is a rich avenue for potential study, and one that stands to offer many insights into attributional processes, stereotyping, and children's developing understanding of risk and resilience.

\section{CONCLUSION}

In the present study, indigenous South African children were more likely than African-American children to report essentialist beliefs about aggression, and were more likely to endorse sociomoral stability beliefs. In addition, across both samples, these beliefs were positively correlated. These findings suggest that differences in environmental context (e.g. cultural differences, differences in environmental input) must be taken into account when exploring the development of children's causal-explanatory frameworks, and that our understanding of the ecology of childhood could be strengthened by a systematic examination of the forces behind these differences.

\section{ACKNOWLEDGEMENTS}

The authors wish to thank Brian Compton for assistance with computer programming. The authors would especially like to thank the administrators, teachers, parents, and children at Neighborhood House Association's Head Start Program, the San Diego City Schools' 6-to-6 Program, and the students and staff of Boskop primary school in Johannesburg, South Africa.

\section{Notes}

1. Rates of violent crime in the neighbourhoods studied during the study years were nearly six times higher for the South African sample than for the United States sample (29.20 per 1000 people in the population for the South African sample versus 5.86 per 1000 people in the population for the United States sample; San Diego Police Department, 2005; South African Crime Service, 2005).

2. Kuder-Richardson-20 (KR-20) is a preferred means of calculating internal consistency when response options are dichotomous (Tabachnick \& Fidell, 2007).

3. Note that this KR-20 is quite weak, which is unsurprising given evidence of substantial variability in children's estimations of efficacy across different intervention strategies (Giles \& Heyman, 2004). 


\section{REFERENCES}

Barbarin, O. A., \& Richter, L. M. (2001). Mandela's children: Growing up in post-apartheid South Africa. New York: Routledge.

Barbarin, O. A., Richter, L. M., \& deWet, T. (2001). Exposure to violence, coping resources, and psychological adjustment of South African children. American Journal of Orthopsychiatry, 71, 16-25.

Baron-Cohen, S. (1995). Mindblindness: An essay on autism and theory of mind. Cambridge, MA: MIT Press.

Bartsch, K., \& Wellman, H.M. (1995). Children talk about the mind. New York: Oxford University Press.

Briere, J. N., \& Elliott, D. M. (1994). Immediate and long-term impacts of sexual abuse. The Future of Children, 2, 54-69.

Bruner, J. (1990). Acts of meaning. Cambridge, MA: Harvard University Press.

Carey, S. (1985). Conceptual change in childhood. Cambridge, MA: MIT Press.

Choi, I., Nisbett, R. E., \& Norenzayan, A. (1999). Causal attribution across cultures: Variation and universality. Psychological Bulletin, 125, 47-63.

Conoley, J. C., \& Goldstein, A. P. (2004). The known, unknown, and future of violence reduction. In A. P. Goldstein, J. C. Conoley, \& J. Close (Eds.), School violence intervention: A practical handbook (2nd ed.) (pp. 527-530). New York: Guilford Press.

Dawes, A. (1994). The effects of political violence on socio-moral reasoning and conduct. In D. Donald \& A. Dawes (Eds.), Childhood \& adversity: Psychological perspectives from South African research (pp. 200-219). Claremont, South Africa: David Philip Publishers.

Deacon, R. (1991). Hegemony, essentialism and radical history in South Africa. South African Historical Journal, 24, 166-184.

Dweck, C. S. (1999). Self-theories: Their role in motivation, personality, and development. Ann Arbor, MI: Edwards Brothers.

Dweck, C. S., Kamins, M., \& Mueller, C. M. (1997). Praise, criticism, and motivational vulnerability. Paper presented at the biennial meeting of the Society for Research in Child Development, Washington, DC.

Dweck, C. S., \& Leggett, E. L. (1988). A social-cognitive approach to motivation and personality. Psychological Review, 95, 256-273.

Eccles, J. S., \& Jacobs, J. E. (1986). Social forces shape math attitudes and performance. Signs, 11, 367-380.

Fischer, K. W., \& Ayoub, C. (1994). Affective splitting and dissociation in normal and maltreated children: Developmental pathways for self in relationships. In D. Cicchetti, \& S. L. Toth (Eds.), Disorders and dysfunctions of the self (pp. 149-222). Rochester, NY: University of Rochester Press.

Gelman, S. A. (2003). The essential child: Origins of essentialism in everyday thought. New York: Oxford University Press.

Gelman, S. A., Coley, J. D., \& Gottfried, G. M. (1994). Essentialist beliefs in children: The acquisition of concepts and theories. In L. A. Hirschfeld \& S. A. Gelman (Eds.), Mapping the mind: Domain specificity in cognition and culture (pp. 341-365). New York: Cambridge University Press.

Gelman, S. A., \& Heyman, G. D. (1999). Carrot-eaters and creature-believers: The effects of lexicalization on children's inferences about social categories. Psychological Science, 10, 489-493.

Gelman, S. A., Heyman, G. D., \& Legare, C. H. (2005). Developmental changes in the coherence of essentialist beliefs. Paper presented at the biennial meeting of the Society for Research in Child Development, Atlanta, GA.

Gervey, B. M., Chiu, C., Hong, Y., \& Dweck, C. S. (1999). Differential use of person information in decisions about guilt versus innocence: The role of implicit theories. Personality and Social Psychology, 25, 17-27.

Giles, J. W. (2003). Children's essentialist beliefs about aggression. Developmental Review, 23, 413-443.

Giles, J. W. (2005). On murderers and sex offenders: The sociocognitive consequences of using noun labels to refer to people who perpetrate violence. Unpublished manuscript. 
Giles, J. W., \& Heyman, G. D. (2003). Preschoolers' beliefs about the stability of antisocial behaviour: Implications for navigating social challenges. Social Development, 12, 182-197.

Giles, J. W., \& Heyman, G. D. (2004). Conceptions of aggression and withdrawal in early childhood. Infant and Child Development, 13, 407-421.

Giles, J. W., \& Heyman, G. D. (2005). Young children's beliefs about the relationship between gender and aggressive behaviour. Child Development, 76, 107-121.

Giles, J. W., Sullivan, C. E., \& Beaufort, A. (2007). Age-related patterns in reasoning about race and aggression. Manuscript in preparation.

Gold, E. R. (1986). Long-term effects of sexual victimization in childhood: An attributional approach. Journal of Consulting and Clinical Psychology, 54, 471-475.

Gopnik, A., \& Wellman, H. M. (1994). The theory theory. In L. Hirschfeld \& S. Gelman (Eds.), Mapping the mind: Domain specificity in cognition and culture (pp. 257-293). Cambridge, UK: Cambridge University Press.

Graham, S. (1984). Communicating sympathy and anger to Black and White children: The cognitive (attributional) consequences of affective cues. Journal of Personality and Social Psychology, 47, 40-54.

Graham, S. (1992). 'Most of the subjects were white and middle class': Trends in published research on African Americans in selected APA journals, 1970-1989. American Psychologist, 47, 629-639.

Hacking, I. (1995). The looping effects of human kinds. In D. Sperber, D. Premack, \& A. J. Premack (Eds.), Causal cognition: A multidisciplinary debate (pp. 351-394). New York: Clarendon Press/Oxford University Press.

Haslam, N. O. (1998). Natural kinds, human kinds, and essentialism. Social Research, 65, 291-314.

Haslam, N. O., \& Levy, S. R. (2006). Essentialist beliefs about homosexuality: Structure and implications for prejudice. Personality and Social Psychology Bulletin, 32, 471-485.

Heyman, G. D., \& Dweck, C. S. (1998). Children's thinking about traits: Implications for judgments of the self and others. Child Development, 69, 392-403.

Heyman, G. D., Dweck, C. S., \& Cain, K. M. (1992). Young children's vulnerability to selfblame and helplessness: Relationship to beliefs about goodness. Child Development, 63, 401-415.

Heyman, G. D., \& Gelman, S. A. (2000). Beliefs about the origins of human psychological traits. Developmental Psychology, 36, 663-678.

Heyman, G. D., \& Giles, J. W. (2006). Gender and psychological essentialism. Enfance, 58, 293-310.

Heyman, G. D., \& Giles, J. W. (2004). Valence effects in reasoning about evaluative traits. Merrill-Palmer Quarterly, 50, 86-109.

Hickling, A. K., \& Wellman, H. M. (2001). The emergence of children's causal explanations and theories: Evidence from everyday conversation. Developmental Psychology, 37, 668683.

Hirschfeld, L. A. (1996). Race in the making: Cognition, culture, and the child's construction of human kinds. Cambridge, MA: MIT Press.

Hofstede, G. (1980). Culture's consequences: International differences in work-related values. Beverly Hills, CA: Sage.

Inagaki, K., \& Hatano, G. (1993). Young children's understanding of the mind-body distinction. Child Development, 64, 1534-1549.

Kelley, H. H. (1967). Attribution theory in social psychology. Nebraska Symposium on Motivation, 15, 192-238.

La Fontaine, J. S. (1985). Person and individual: Some anthropological reflections. In M. Carrithers, S. Collins, \& S. Lukes (Eds.), The category of the person: Anthropology, philosophy, history (pp. 123-140). New York: Cambridge University Press.

Leslie, A. (1995). ToMM, ToBy, and Agency: Core architecture and domain specificity. In S. Gelman (Ed.), Domain specificity in cognition and culture. New York: Cambridge University Press.

Levy, S. R., \& Dweck, C. S. (1999). The impact of children's static versus dynamic conceptions of people on stereotype formation. Child Development, 70, 1163-1180.

Lillard, A. (1998). Ethnopsychologies: Cultural variations in theory of mind. Psychological Bulletin, 123, 3-32. 
Lockhart, K. L., Chang, B., \& Story, T. (2002). Young children's beliefs about the stability of traits: Protective optimism? Child Development, 73, 1408-1430.

Lutz, C. (1985). Ethnopsychology compared to what? Explaining behaviour and consciousness among the Ifaluk. In G. M. White, \& J. Kirkpatrick (Eds.), Person, self, and experience: Exploring Pacific ethnopsychologies (pp. 35-79). Berkeley, CA: University of California Press.

Maas, E., Marecek, J., \& Travers, J. R. (1978). Children's conceptions of disordered behaviour. Child Development, 49, 146-154.

Mahalingam, R. (2003). Essentialism, culture, and power: Representations of social class. Journal of Social Issues, 59, 733-749.

Martin, C. L., \& Parker, S. (1995). Folk theories about sex and race differences. Personality and Social Psychology Bulletin, 21, 45-57.

Medin, D. L. (1989). Concepts and conceptual structure. American Psychologist, 44, 14691481.

Medin, D. L., \& Heit, E. (1999). Categorization. In B. J. Bly \& D. E. Rumelhart (Eds.), Cognitive Science (pp. 99-143). San Diego: Academic Press.

Miller, J. G. (1984). Culture and the development of everyday social explanation. Journal of Personality and Social Psychology, 46, 961-978.

Mueller, C. M., \& Dweck, C. S. (1998). Praise for intelligence can undermine children's motivation and performance. Journal of Personality and Social Psychology, 75, 33-52.

Pfeffer, K., Cole, B., \& Dada, K. (1998). Attributions for youth crime among British and Nigerian primary school children. Journal of Social Psychology, 138, 251-253.

Rothbart, M., \& Taylor, M. (1992). Category labels and social reality: Do we view social categories as natural kinds? In G. R. Semin \& K. Fiedler (Eds.), Language, interaction and social cognition (pp. 11-36). London: Sage Publications.

Rowe, D. C., \& Plomin, R. (1981). The importance of nonshared environmental influences in behavioural development. Developmental Psychology, 17, 517-530.

San Diego Police Department (2005). Crime rates per neighborhood per 1,000 population: 20012005. San Diego, CA: City of San Diego.

Schuster, B., Ruble, D. N., \& Weinert, F. E. (1998). Causal inferences and the positivity bias in children: The role of the covariation principle. Child Development, 69, 1577-1596.

Shweder, R. A., \& Bourne, E. J. (1991). Does the concept of the person vary crossculturally? In R. A. Shweder (Ed.), Thinking through culture: Expeditions in cultural psychology (pp. 113-155). Cambridge, MA: Harvard University Press.

Snyman, G. (2005, January). Constructing and deconstructing identities in post-apartheid South Africa: A case of hybridity versus untainted Africanity? Paper presented at the rhetoric of identity conference, Center for Rhetorics and Hermeneutics, Redlands, CA.

South African Crime Service (2005). Crime in the RSA for April to March 2001/2002 to 2004/ 2005. Johannesburg, South Africa: South African Crime Information Analysis Centre.

Steinberg, L., \& Scott, E. S. (2003). Less guilty by reason of adolescence: Developmental immaturity, diminished responsibility, and the juvenile death penalty. American Psychologist, 58, 1009-1018.

Tabachnick, B. G., \& Fidell, L. S. (2007). Using multivariate statistics (5th ed.). Glenview, IL: Harper Collins.

Verkuyten, M. (2003). Discourses about ethnic group (de-)essentialism: Oppressive and progressive aspects. British Journal of Social Psychology, 42, 371-391.

Weiner, B. (1974). Achievement motivation and attribution theory. Morristown, NJ: General Learning Press.

Wellman, H. M., \& Gelman, S. A. (1998). Knowledge acquisition in foundational domains. In W. Damon (Ed.), D. Kuhn \& R. S. Siegler (Vol. Eds.), Handbook of child psychology: Vol. 2. Cognition, perception, and Language (pp. 523-574). New York: Wiley.

Whiting, B. B. (1996). The effect of social change on concepts of the good child and good mothering: A study of families in Kenya. Ethos, 24, 3-35.

Yzerbyt, V., Rocher, S., \& Schadron, G. (1997). Stereotypes as explanations: A subjective essentialistic view of group perception. In R. Spears, P. J. Oakes, N. Ellemers, \& S. A. Haslam (Eds.), The social psychology of stereotyping and group life (pp. 20-50). Oxford: Blackwell. 